\title{
A Blueprint for Planning and Implementing a Transgender Health Program
}

\author{
Anna M. Morenz, MD \\ Hilary Goldhammer, $S M^{3}$ \\ Cei A. Lambert, MFA \\ Ruben Hopwood, MDiv, PbD ${ }^{4,5}$ \\ Alex S. Keurogblian, MD, MPH $H^{2,3,6}$ \\ 'Department of Medicine, University of \\ Washington, Seattle, Washington \\ ${ }^{2}$ Harvard Medical School, Boston, \\ Massachusetts \\ ${ }^{3}$ National LGBT Health Education Center \\ at The Fenway Institute, Fenway Health, \\ Boston, Massachusetts
}

${ }^{4}$ Transgender Health Program, Medical Department, Fenway Health, Boston, Massachusetts

${ }^{5}$ The Danielsen Institute at Boston University, Boston, Massachusetts

${ }^{6}$ Department of Psychiatry, Massachusetts General Hospital, Boston, Massachusetts

Conflicts of interest: authors report none.

\section{CORRESPONDING AUTHOR}

Alex S. Keuroghlian, MD, MPH

The Fenway Institute

1340 Boylston Street

Boston, MA, 02215

akeuroghlian@partners.org

\begin{abstract}
Transgender and gender-diverse people face multiple barriers to accessing appropriate health care, including denial of service, harassment, and lack of clinician knowledge. This article presents a blueprint for planning and implementing a transgender health program within a primary care practice in order to enhance the capacity of the health care system to meet the medical and mental health needs of this underserved population. The steps described, with emphasis on elements specific to transgender care, include conducting a community needs assessment, gaining commitment from leadership and staff, choosing a service model and treatment protocols, defining staff roles, and creating a welcoming environment.
\end{abstract}

Ann Fam Med 2020;18:73-79. https://doi.org/10.1370/afm.2473.

$\mathrm{T}$ ransgender and gender-diverse people have a gender identity that differs from the one traditionally associated with the sex they were assigned at birth. These identities may include trans feminine, trans masculine, and non-binary identities. A high prevalence of suicide attempts, HIV infection, substance use disorders, and other health inequities affect the transgender and gender-diverse community, ${ }_{1}^{1-4}$ and numerous barriers such as harassment and discrimination impact the community's access to care. ${ }^{1,4-6}$ Many transgender and gender-diverse people seek medical interventions to affirm their gender identity, ${ }_{1}$ but few primary care programs provide gender-affirming hormone therapy, surgical referrals, or wrap-around services to an increasingly visible transgender and genderdiverse population. As educators and clinical experts on transgender health care, we field numerous requests from primary care organizations to help with planning and implementing transgender health programs. In this article, we respond to those requests by presenting a "blueprint" that can be adapted by primary care practices of different sizes and settings. Our flexible recommendations are based on expertise gained from operating (1) a transgender health program integrated within an urban health center that has served over 6,000 transgender and gender-diverse primary care patients, ${ }^{7}$ and (2) a national center funded and authorized by the US government to provide technical assistance on the implementation of over 150 transgender health programs in communities across the nation. ${ }^{8}$

\section{NEEDS ASSESSMENTS}

For organizations with the resources to conduct a formal needs assessment, we offer several recommendations below. Practices without such capacity may forgo the needs assessment and instead begin providing gender-affirming medical treatments for transgender and gender-diverse patients after accessing relevant training and guidelines, and by building a referral network for surgeries and other external services.

\section{Community Needs}

A needs assessment with the surrounding transgender and gender-diverse community helps tailor services to the local setting while ensuring inclu- 
sion of gender-diverse voices. In areas with defined and engaged transgender and gender-diverse populations, using traditional assessment methods, such as focus groups, community leader interviews, and/or town forums may suffice. Offering light meals for participants shows consideration for those who may be experiencing homelessness or unemployment. To assess patient perceptions of your organization's current competence in serving transgender and gender-diverse patients, practices can place comment boxes in waiting rooms and ask about gender identity on patient satisfaction surveys. The state health department may also have information on transgender health disparities and needs. In less open communities, hosting online focus groups and/or anonymous surveys through social media sites may yield more robust findings. The Supplemental Appendix provides examples of published community needs assessments and of sample assessment questions (Supplemental Appendix, available at http://www.AnnFamMed.org/ content/18/1/73/suppl/DC1/).

\section{Organizational Capacity and Needs}

It is also important to assess existing capacity and needs within your organization and in the surrounding area. Taking informal polls at staff meetings and regional conferences, on message boards, or in discussions with human resource executives and diversity and inclusion committees can help uncover who is already providing medical or mental health care for transgender and gender-diverse patients, who has training or experience, and who has a strong interest in learning. An internal organizational needs assessment ${ }^{9}$ and ongoing discussions with leadership can help assess other areas of need and opportunity within the organization. For example, does the electronic health record software accommodate collecting information on gender identity? How do staff currently self-report their comfort and knowledge in transgender health care? Are there ways to incorporate staff training on sensitive and effective communication with transgender and genderdiverse people into regular diversity training? Are there clinic hours that can be used for transgender health?

\section{PLANNING AND IMPLEMENTATION TEAM}

Interested personnel can form a planning and implementation team with a minimum of 2 "champions" who meet regularly and lead the change effort. Typically, at least 1 champion is a primary care clinician. It is helpful for the other champion to have a nonclinical position, and for at least 1 of the champions to have a decision-making role in the organization to help facilitate support from leadership. Ideally, the team consists of people who represent the local transgender and gender-diverse community; if this is not possible, the team can attempt to assemble and meet regularly with a community advisor or group.

\section{ORGANIZATIONAL BUY-IN}

Starting a new program, especially one focused on a stigmatized population, can generate staff concerns and resistance. To gain buy-in from leadership and colleagues, champions can generate enthusiasm for the program through staff presentations that emphasize how offering transgender health care can position the organization at the vanguard of reducing disparities, and how gender-affirming care aligns with the principles of medical ethics, such as beneficence and justice. Other strategies include holding question-and-answer sessions with staff and inviting a panel of transgender and gender-diverse people to share their personal experiences seeking health care (alternatively, showing films with transgender themes and holding a discussion afterwards). Champions can enhance motivation among colleagues by conducting follow-up presentations that demonstrate ways in which the ideas and interests of staff members are being integrated into the program.

Cost concerns can be alleviated by explaining that several US medical professional societies support insurance coverage for transgender health care, ${ }^{10}$ and that a large percentage of transgender and genderdiverse patients require multiple visits per year (eg, for hormone therapy and surgical referrals) and often have strong networks who can bring in additional patients, even from outside the usual catchment area. Given the volume of need and the lack of care options elsewhere, it is likely these services could be revenue-neutral if not revenue-generating.

\section{SERVICE MODELS}

Depending on the setting, needs, and resources of each organization and community, a transgender health program can be as streamlined as 1 or 2 clinicians providing hormone therapy within a welcoming primary care practice, or as comprehensive as a "onestop shop" within an academic hospital offering the full range of gender-affirming services, including primary care, endocrinology, gynecology, mental health, voice therapy, and surgical care. Many programs start with a small core team of primary care clinicians who initiate and monitor hormone therapy, supported by an administrative staff person who is well-versed in genderinclusive language and insurance navigation, and who can help clinicians coordinate referral services as needed. Programs may also initially tailor services for a subset of the local transgender and gender-diverse 


\section{Figure 1. Suggested components of a comprehensive transgender health program.}

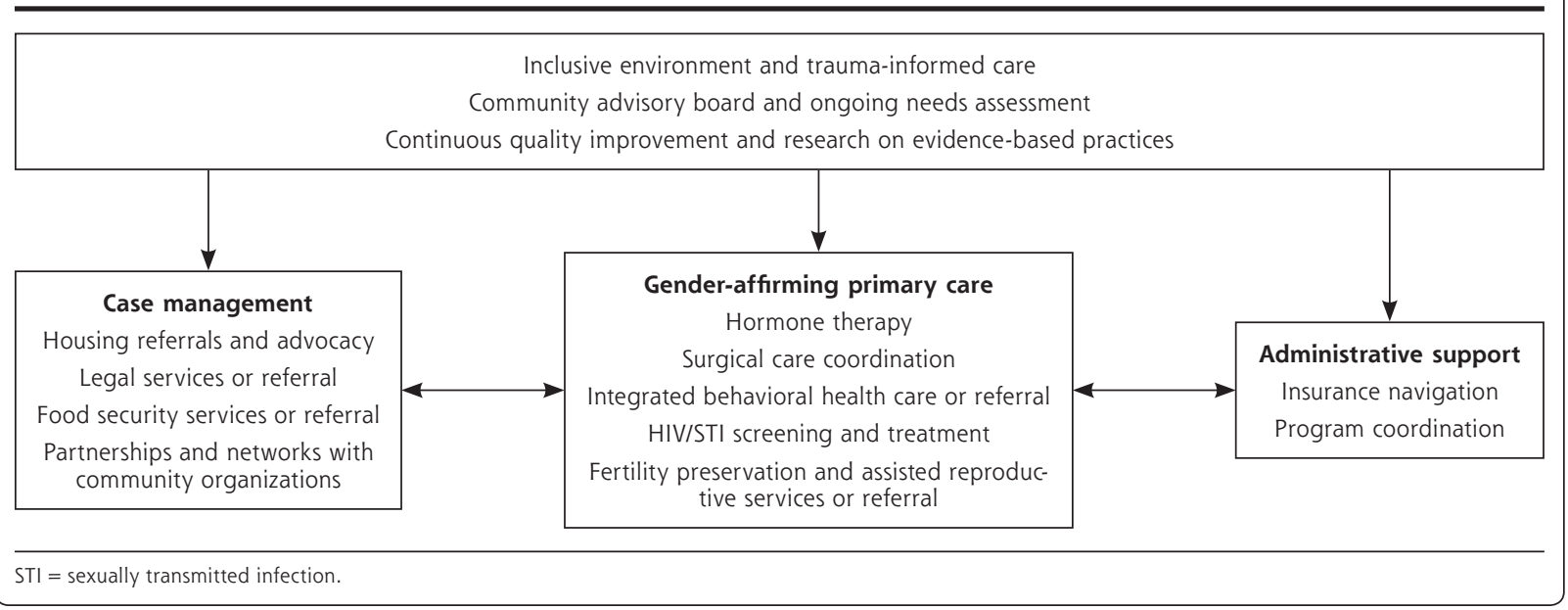

community (eg, transgender and gender-diverse women of color) shown to have the greatest need during the assessment phase. Some teams eventually expand to other clinicians and build more comprehensive, integrated programs that provide an ideal model of care. This model includes in-house services most relevant to the local transgender and gender-diverse community, possibly aligning primary medical care with mental health counseling, substance use disorder treatment, HIV and sexually transmitted infection (STI) prevention and treatment, obstetrics and gynecology, case management for accessing basic needs like food and housing, legal and advocacy services for insurance coverage and name and gender change on identity documents, and/or options or referrals for fertility preservation and assisted reproduction (Figure 1). Because transgender health is understudied, some programs have formed research arms to contribute to the development of evidence-based practices. ${ }^{7}$ Before expanding, program teams can use continuous quality improvement methods to evaluate and adjust their systems and clinical practices accordingly.

Typically, transgender health programs are either (1) embedded within existing primary care settings so that transgender and gender-diverse patients see specific clinicians during regular office hours in the same space as all other patients $s_{i}$ (2) fully integrated so that all clinicians are prepared to care for transgender and gender-diverse patients, or (3) offered as a separate, dedicated program that has a different location or designated practice times (eg, after hours). A separate program might be chosen if transgender and genderdiverse patient safety or confidentiality is a concern, or if logistical or cultural barriers currently prevent incorporation within the mainstream clinical practice. If the program is separate, it is vital that it does not become ostracizing or unequal in quality. For embedded programs, it is important that all clinicians demonstrate adequate understanding and respect for gender diversity in cases of urgent care situations when a transgender or gender-diverse patient's primary care clinician is not available. ${ }^{11,12}$

All transgender health programs can benefit from developing broad relationships with external agencies, community-based organizations, and individual practitioners who provide a range of services and can function as a network for knowledge-sharing and referrals. These connections can include lesbian, gay, bisexual, transgender, queer, intersex, and asexual (LGBTQIA+) community centers, AIDS service organizations, substance use disorder treatment centers, departments of public health, mental health practitioners, endocrinologists, and surgeons. When building referral systems, it can be helpful to develop a memorandum of understanding that defines the terms and responsibilities of each organization in order to meet expectations and maintain accountability. In addition, ongoing communication via in-person feedback, web acknowledgments, and handwritten thank-you notes about how these services improve outcomes can go a long way toward nurturing relationships with partner organizations. See Table 1 for examples of transgender health program models.

\section{TREATMENT PROTOCOLS AND CLINICAL TRAINING}

After years of referring transgender and gender-diverse patients to specialty clinics and endocrinologists, transgender health experts have come to agree that gender-affirming hormone therapy can be safely delivered as part of routine care by a trained primary care 
clinician. ${ }^{14,15}$ Furthermore, most adult patients do not require mental health counseling in order to receive hormone therapy; rather, the primary care clinician can determine if the patient has the capacity to make an informed medical decision about gender-affirming treatment and if any existing mental health conditions are reasonably well-controlled. ${ }^{16}$ Patients need only be referred to a mental health specialist to address untreated psychiatric or substance use disorders. ${ }^{14}$ This approach, which is part of an informed consent-based model, avoids unnecessary and prolonged barriers to potentially life-saving treatment.

Although no single standard of treatment exists, several evidence-based protocols offer recommendations for hormone therapies as well as general preventive and mental health care (Table 2). Primary care clinicians can learn to safely and effectively provide hormone therapy, preventive care, and surgical follow-up through basic training and practice. Despite common concerns that transgender health care is complicated, it is in fact as straightforward as managing common chronic diseases. The general approach to genderaffirming hormone therapy first requires counseling patients on the benefits and potential risks of treatment, including options for fertility preservation. Typically, the next step involves delivering estradiol for feminizing treatment, or testosterone for masculinizing treatment. Therapy may also consist of an additional medication to suppress endogenous hormones, particularly in the case of feminization. Once therapy has begun, clinicians track progress toward desired effects and monitor for potential side effects.

Although only a handful of clinical training programs offer transgender health care within their existing standardized curricula, several continuing education programs are available (Table 2). Sometimes a core team (eg, a physician, nurse, and mental health clinician) initially trains together and then meets regularly to discuss cases. A program can also begin with a single clinician who gradually trains others 
within the organization through shadowing opportunities, consultation, and didactic learning.

\section{STAFF TRAINING AND COMPETENCIES}

It is very important for all patient-facing staff (clinical and nonclinical) to receive a foundational level of training in cultural sensitivity and effective communication with transgender and gender-diverse patients. ${ }^{8}$ Key competencies include using patients' correct names and pronouns, maintaining confidentiality of gender identities, avoiding assumptions about gender, being open to nonbinary gender identities, and avoiding questions not pertinent to care. ${ }^{12,17,18}$ In order for the program to be truly inclusive, the workplace culture must ensure that chatter behind closed doors does not differ from patient-facing language. Suggested roles and corresponding competencies for staff members are presented in Table 3. The roles of a program's staff will vary depending on the patient population size and the breadth of services offered. For most programs, many of the roles can be combined or provided through referrals, and existing staff can be trained in the competencies.

If hiring new staff, programs should aim to hire transgender and gender-diverse employees, some of whom may identify themselves during the needs-assessment process. Career marketing materials ought to state that personnel of all gender identities and expressions are sought ${ }_{i}$ employee policies should explicitly protect against discrimination based on gender identity or expression. At the same time, programs ought to take caution against unconsciously tokenizing or outing transgender and gender-diverse staff, or expecting these staff to educate their colleagues or become public spokespersons unless they wish to serve in this role.

\section{COVERING FINANCIAL COSTS OF CARE}

Common barriers to coverage of financial costs are insurance policies that exclude gender-affirming hormone therapy and/or surger- ies, and cases in which a patient's anatomy necessitates different screening than what may be assumed based on the gender marker in their identifying documents or health records. ${ }^{19}$ Clinicians often need to appeal for insurance coverage with a rationale for care. For larger programs, it may be necessary to hire a program coordinator or to train care navigators to help advocate for treatment coverage.

\section{ELECTRONIC HEALTH RECORDS}

Collecting and recording patient data on gender identity (and sexual orientation) in the electronic health record (EHR) has been recommended as critical for providing patient-centered care and reducing health disparities. ${ }^{20,18}$ Although all EHR systems certified for Meaningful Use are now required to have the capacity to record gender identity, many systems still require adjustments. Ideally, the EHR will also allow for a

Table 3. Suggested Staff Roles and Competencies for a Primary Care Transgender Health Program

\begin{tabular}{|c|c|}
\hline Staff Member & Suggested Roles and Competencies \\
\hline $\begin{array}{l}\text { Primary care/family } \\
\text { medicine clinician } \\
\text { (eg, physician, nurse } \\
\text { practitioner, physician } \\
\text { assistant) }\end{array}$ & $\begin{array}{l}\text { - Provides hormone therapy according to standards of care } \\
\text { - Provides routine primary care based on anatomy and behavior, } \\
\text { not identity } \\
\text { - Coordinates surgical care; provides perioperative and post- } \\
\text { operative care } \\
\text { - Does not assume all patients want masculinizing or feminizing } \\
\text { treatment } \\
\text { - Supports patients with nonbinary gender identities } \\
\text { - Is open to alternative strategies for anatomy-based procedures, } \\
\text { such as a self-administered cervical swab for human papilloma- } \\
\text { virus testing } \\
\text { - Participates in shared decision making with patients } \\
\text { - Is nonjudgmental when addressing substance use, silicone injec- } \\
\text { tion, sex work, and other stigmatized behaviors }\end{array}$ \\
\hline $\begin{array}{l}\text { Behavioral health clini- } \\
\text { cian (eg, licensed } \\
\text { social worker, licensed } \\
\text { mental health coun- } \\
\text { selor, psychologist) }\end{array}$ & $\begin{array}{l}\text { - Helps patients navigate social, personal, and familial aspects } \\
\text { of gender identity and expression, but does not act as a gate- } \\
\text { keeper to medical gender affirmation } \\
\text { - Writes letters of support for surgeries and other gender-affirming } \\
\text { procedures when required by insurance providers or surgeons } \\
\text { - Offers counseling and support groups for transgender and } \\
\text { gender-diverse communities } \\
\text { - Provides counseling and treatment for substance use disorders }\end{array}$ \\
\hline Case manager/nurse & $\begin{array}{l}\text { - Develops and maintains relationships with gender-affirming local } \\
\text { agencies; navigates referrals }\end{array}$ \\
\hline $\begin{array}{l}\text { Front desk/patient ser- } \\
\text { vice representative }\end{array}$ & $\begin{array}{l}\text { - Talks to patients with no assumptions about gender identity } \\
\text { - Communicates sensitively with patients about dissimilarities } \\
\text { between name and gender on insurance documents, legal iden- } \\
\text { tification, and medical records }\end{array}$ \\
\hline Medical assistant/nurse & $\begin{array}{l}\text { - Ensures that gender and name information is communicated } \\
\text { seamlessly from front desk to clinicians }\end{array}$ \\
\hline $\begin{array}{l}\text { Program director/coor- } \\
\text { dinator (for programs } \\
\text { with large transgender } \\
\text { and gender-diverse } \\
\text { patient populations) }\end{array}$ & $\begin{array}{l}\text { - Oversees program operations, schedules and leads team meet- } \\
\text { ings, manages the budget, supports patients with insurance } \\
\text { issues and name changes, ensures all staff are trained, helps with } \\
\text { surgical authorizations and other paperwork, and helps with } \\
\text { recruitment of staff and patients }\end{array}$ \\
\hline
\end{tabular}


patient's name (which may differ from the name on insurance or identification documents) and correct pronouns to be collected at patient registration, recorded and displayed in the EHR for all staff to see before interacting with the patient, and will also include anatomic inventories, as well as procedures and medications specific to gender affirmation. ${ }^{21-23}$

\section{INCLUSIVE, TRAUMA-INFORMED ENVIRONMENTS}

To create more welcoming care environments, organizations can offer clearly labeled all-gender restrooms and prominently post nondiscrimination policies that include gender identity and expression. Intake forms may need modifications to include the full range of gender identities and sexual orientations, chosen names, pronouns, and names on insurance and legal documents. ${ }^{12,23}$ Because transgender and gender-diverse people experience high levels of trauma and stress related to minority status, it is also recommended to adopt a trauma-informed approach. Trauma-informed care for transgender and genderdiverse people means recognizing that patients may need interventions to address their trauma, and may need additional choices and autonomy to engage in particular kinds of medical care, ${ }^{24-26}$ such as a selfadministered cervical swab for human papillomavirus testing among trans masculine people. ${ }^{27}$ Transgender and gender-diverse patients may also react with strong emotions if something occurs during a primary care encounter that reminds them of a past traumatic experience or leaves them feeling threatened. ${ }^{28}$

\section{PROGRAM COSTS AND FUNDING}

Most programs need minimal start-up funding. Free or low-cost trainings and resources can be accessed through online learning platforms, local university LGBTQIA+ programs, or public health departments (Table 2). Clinicians can also include transgender health training within their continuing medical education budget. Program champions can deliver promotional and informational messages via existing channels, such as the organization's website, newsletters, and social media platforms; champions can also set up interviews with local journalists and can give presentations to the community at local LGBTQIA+ gathering places. Some costs may be incurred if electronic health records require extensive modifications, or if new restroom signage is needed. Common funding sources include public health departments, foundations/private donations, and large nonprofit organizations

\section{CONCLUSION}

Creating a transgender health program provides a much-needed service for an underserved population that experiences significant health inequities. A program that offers community-tailored medical and mental health services, case management, legal advocacy, and more, will provide a unique opportunity to holistically improve wellness and quality of life for transgender and gender-diverse people. As more programs develop globally, staff can join the growing and passionate network of clinical practice teams who are committed to health care, innovation, and equity for transgender and gender-diverse communities.

To read or post commentaries in response to this article, see it online at http://www.AnnFamMed.org/content/18/1/73.

Key words: transgender health program; transgender service model; gender-affirming care; hormone therapy protocol; gender identity; health care access; primary care; gender dysphoria; clinical practice guidelines; transgender; gender-diverse communities

Submitted October 22, 2018; submitted, revised, May 3, 2019; accepted May 21, 2019.

Supplemental materials: Available at http://www.AnnFamMed. org/content/18/1/73/suppl/DC1/.

\section{References}

1. James SE, Herman JL, Rankin S, Keisling M, Mottet $L$, Anafi M. The Report of the 2015 U.S. Transgender Survey. Washington, DC: National Center for Transgender Equality; 2016. https:// transequality.org/sites/default/files/docs/usts/USTS-Full-ReportDec17.pdf. Published Dec 2016. Accessed Jul 11, 2018.

2. Baral SD, Poteat T, Strömdahl S, Wirtz AL, Guadamuz TE, Beyrer C. Worldwide burden of HIV in transgender women: a systematic review and meta-analysis. Lancet Infect Dis. 2013;13(3):214-222.

3. Keuroghlian AS, Reisner SL, White JM, Weiss RD. Substance use and treatment of substance use disorders in a community sample of transgender adults. Drug Alcohol Depend. 2015;152:139-146.

4. The Institute of Medicine. The Health of Lesbian, Gay, Bisexual, and Transgender (LGBT) People: Building a Foundation for Better Understanding. Washington, DC: National Academies Press; 2011.

5. Bradford J, Reisner SL, Honnold JA, Xavier J. Experiences of transgender-related discrimination and implications for health: results from the Virginia Transgender Health Initiative Study. Am J Public Health. 2013;103(10):1820-1829.

6. Safer JD, Coleman E, Feldman J, et al. Barriers to healthcare for transgender individuals. Curr Opin Endocrinol Diabetes Obes. 2016; 23(2):168-171.

7. Reisner SL, Bradford J, Hopwood R, et al. Comprehensive transgender healthcare: the gender affirming clinical and public health model of Fenway Health. J Urban Health. 2015;92(3):584-592.

8. Ard KL, Keuroghlian AS. Training in sexual and gender minority health - expanding education to reach all clinicians. $N$ Engl J Med. 2018;379(25):2388-2391

9. Goldhammer H, Maston ED, Kissock LA, Davis JA, Keuroghlian AS. National findings from an LGBT healthcare organizational needs assessment. LGBT Health. 2018;5(8):461-468.

10. Stroumsa D. The state of transgender health care: policy, law, and medical frameworks. Am J Public Health. 2014;104(3):e31-e38. 
11. Hinrichs A, Link C, Seaquist L, Ehlinger P, Aldrin S, Pratt R. Transgender and gender nonconforming patient experiences at a family medicine clinic. Acad Med. 2018;93(1):76-81.

12. Reisner SL, Radix A, Deutsch MB. Integrated and gender-affirming transgender clinical care and research. J Acquir Immune Defic Syndr. 2016;72(Suppl 3):S235-S242.

13. Transgender Law Center. How to Start a Transgender Clinic. Oakland, CA: Transgender Law Center; 2008. https://transgenderlawcenter. org/resources/health/how-to-start-a-transgender-clinic.

14. Coleman E, Bockting W, Botzer M, et al. Standards of care for the health of transsexual, transgender, and gender-nonconforming people, version 7. Int J Transgenderism. 2012;13(4):165-232.

15. White Hughto JM, Reisner SL. A systematic review of the effects of hormone therapy on psychological functioning and quality of life in transgender individuals. Transgend Health. 2016;1(1):21-31.

16. Smith WB, Goldhammer H, Keuroghlian AS. Affirming gender identity of patients with serious mental illness. Psychiatr Serv. 2019; 70(1):65-67.

17. Goldhammer H, Malina S, Keuroghlian AS. Communicating with patients who have nonbinary gender identities. Ann Fam Med. 2018;16(6):559-562.

18. Deutsch MB, Green J, Keatley J, Mayer G, Hastings J, Hall AM; World Professional Association for Transgender Health EMR Working Group. Electronic medical records and the transgender patient: recommendations from the World Professional Association for Transgender Health EMR Working Group. J Am Med Inform Assoc. 2013;20(4):700-703.

19. Learmonth C, Viloria R, Lambert C, Goldhammer H, Keuroghlian AS. Barriers to insurance coverage for transgender patients. Am J Obstet Gynecol. 2018;219(3):272.e1-272.e4.

20. The Joint Commission. Advancing Effective Communication, Cultural Competence, and Patient- and Family-Centered Care for the Lesbian, Gay, Bisexual, and Transgender (LGBT) Community: A Field Guide. Oak Brook, IL: The Joint Commission; 2011.
21. Deutsch MB, Buchholz D. Electronic health records and transgender patients - practical recommendations for the collection of gender identity data. J Gen Intern Med. 2015;30(6):843-847.

22. The National LGBT Health Education Center. Ready, Set, Go! Guidelines and Tips For Collecting Patient Data on Sexual Orientation and Gender Identity. Boston, MA: The Fenway Institute, Fenway Health; 2018. www.lgbthealtheducation.org/publication/ready-set-goguidelines-tips-collecting-patient-data-sexual-orientation-genderidentity. Published Jan 2018. Accessed Sep14, 2018.

23. Grasso C, McDowell MJ, Goldhammer H, Keuroghlian AS. Planning and implementing sexual orientation and gender identity data collection in electronic health records. J Am Med Inform Assoc. 2019; 26(1):66-70.

24. Machtinger EL, Cuca YP, Khanna N, Rose CD, Kimberg LS. From treatment to healing: the promise of trauma-informed primary care. Womens Health Issues. 2015;25(3):193-197.

25. Brezing C, Ferrara M, Freudenreich O. The syndemic illness of HIV and trauma: implications for a trauma-informed model of care. Psychosomatics. 2015;56(2):107-118.

26. Substance Abuse and Mental Health Services Administration. SAMHSA's Concept of Trauma and Guidance for a Trauma-Informed Approach. Rockville, MD: Substance Abuse and Mental Health Services Administration; 2014.

27. Reisner SL, Deutsch MB, Peitzmeier SM, et al. Comparing self- and provider-collected swabbing for HPV DNA testing in female-to-male transgender adult patients: a mixed-methods biobehavioral study protocol. BMC Infect Dis. 2017;17(1):444.

28. Reisner SL, White Hughto JM, Gamarel KE, Keuroghlian AS, Mizock L, Pachankis JE. Discriminatory experiences associated with posttraumatic stress disorder symptoms among transgender adults. J Couns Psychol. 2016;63(5):509-519. 